University for Business and Technology in Kosovo

UBT Knowledge Center

UBT International Conference

2018 UBT International Conference

Oct 27th, 3:15 PM - 4:45 PM

\title{
Seasonal Dynamics of Respiratory Tract Infections from Group A Streptococcus Beta Hemoliticus in the Region of Gjakova, Kosovo
}

\author{
Arianeta Nura \\ University for Business and Technology, arianeta.nura@ubt-uni.net \\ Naser Ramadani \\ National Institute of Public Health of Kosovo \\ Etleva Hamzaraj \\ University of Tirana
}

Follow this and additional works at: https://knowledgecenter.ubt-uni.net/conference

Part of the Food Science Commons

\author{
Recommended Citation \\ Nura, Arianeta; Ramadani, Naser; and Hamzaraj, Etleva, "Seasonal Dynamics of Respiratory Tract \\ Infections from Group A Streptococcus Beta Hemoliticus in the Region of Gjakova, Kosovo" (2018). UBT \\ International Conference. 188. \\ https://knowledgecenter.ubt-uni.net/conference/2018/all-events/188
}

This Event is brought to you for free and open access by the Publication and Journals at UBT Knowledge Center. It has been accepted for inclusion in UBT International Conference by an authorized administrator of UBT Knowledge Center. For more information, please contact knowledge.center@ubt-uni.net. 


\title{
Seasonal Dynamics of Respiratory Tract Infections from Group A Streptococcus Beta Hemoliticus in the Region of Gjakova, Kosovo
}

\author{
Arianeta Nura ${ }^{1}$, Naser Ramadani ${ }^{2}$, Etleva Hamzaraj ${ }^{2}$ \\ ${ }^{1}$ Faculty of food and Technology Sciences, UBT. \\ ${ }^{2}$ National Institute of Public Health of Kosova \\ ${ }^{2}$ Department of Biology, Faculty of Natural Sciences, University of Tirana \\ arianeta.nura@ubt-uni.net
}

\begin{abstract}
The aim of this study was to investigate the carrier rates of group A beta hemolytic Streptococcus (GAS) in upper respiratory tract during the various seasons of the year. We have performed a study in population of Gjakova region during the year 2017, were we have analyzed 1590 cases. In the total cases that are studied from us, $84 \%$ has been negative in there culture and $16 \%$ of this cases are resulted positive with presence of GAS. In our study the rate of isolation was $35 \%$ in spring, $14 \%$ in summer, $15 \%$ in autumn and $36 \%$ in winter. The highest frequency of infected individuals was observed in children 0-10 years and in the females.
\end{abstract}

Keywords: Group A Streptococcus beta hemolyticus, Respiratory tract, Seasons, Gjakova region

\section{Introduction}

Group A Streptococcus $\beta$-Hemolyticus, commonly known as Group A Streptococcus (GAS) is a bacteria that causes a range of human infections. Diseases caused by the Lancefield group A Streptococcus - Streptococcus pyogenes, are among the most varied in terms of clinical spectra and severity, ranging from the ubiquitous pharyngitis to rarer life-threatening presentations such as necrotizing fasciitis. The most common infection attributable to GAS is pharyngitis, in children between 5 and 15 years of age. In the laboratory, the bacteria are classified into different hemolytic groups according to their reaction with the blood medium. Those that completely lyse blood cells are classified as $\beta$ Hemolytic Streptococcus [2].

These can be classified into different serological groups using the Lancefield grouping system, a characterization based on the carbohydrate composition of bacterial antigens found on their cell walls [8].

We therefore undertake to perform a systematic review to determine the carrier rates of group A beta hemolytic Streptococcus (GAS) in upper respiratory tract during the various seasons of the year. Invasive $S$. pyogenes infections have attracted increasing levels of attention since the late 1980 s when reports from the USA, Canada, Norway, Sweden and Denmark warned of a possible re-emergence of severe clinical manifestations of $S$. pyogenes, and nonsuppurative sequelae such as rheumatic fever $[7 ; 12 ; 14 ; 6]$. Streptococcus pyogenes is commonly carried in the oropharynx and on intact skin of humans. The genital tract and perianal area are also sites of carriage. Carriage rates vary according to geographical location, climatic factors, season and age [3]. 
Estimates of pharyngeal carriage range from $12-23 \%$ in school-aged children [5;9]. S. pyogenes can also contaminate the environment immediately around carriers and those with disease [10]. Transmission of $S$. pyogenes is usually through direct contact with droplets of saliva or nasal secretions from carriers or persons with clinical infection, or through skin contact, especially contact with infected lesions. The length of incubation is usually fairly short, usually 1-3 days [13].

A wide range of clinical infections are recognized as being caused by Streptococcus pyogenes, including respiratory, cutaneous, soft tissue and systemic infections.

\section{Materials and Methods}

During the period January-December 2017 in the microbiological laboratory of the IPH in Gjakova were analyzed 1590 samples. All the samples have been taken in accordance with the standards set by the literature [4].

Identification of streptococcus pyogenes colonies is done through clinical material planted on the Petri dishes with blood agar which were incubated for 24 hours in $37^{\circ} \mathrm{C}$, and after is made the reading of cultures $(1,11)$. Identification of Streptococcus pyogenes colonies that produce a toxin that causes red blood cell hemolysis (known as Streptococcus beta hemolyticus) and their identification is accelerated by placing a low concentration bacitracin disk (0.02-0.05 IU) in the field of initial planting. In general B-hemolytic zone surrounding colonies has size 2 to 4 times larger than the diameter of the colony itself. If the colonies were few (one or two) they were taken from the main plate and incubated on another plate. Then each field is covered with disk bacitracin. 24 hour after incubation Group A Streptococcus beta hemolyticus causes beta hemolysis.

Determination of antibiotic sensitivity has been made on Petri Plates with the Myller Hynton area or blood agar. Then were evaluated the measured areas: resistant - when around the antibiotic disc were no restriction of bacterial flora $<13 \mathrm{~mm}$; Intermediate resistance 15-17 $\mathrm{mm}$ and sensitive $18-22 \mathrm{~mm}$.

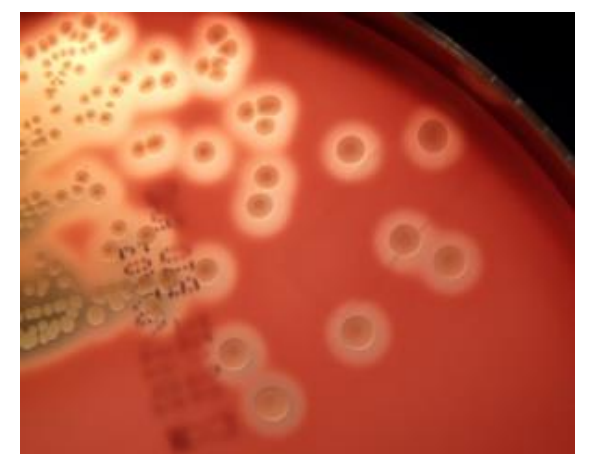

Figure 1. Beta-hemolytic colonies of

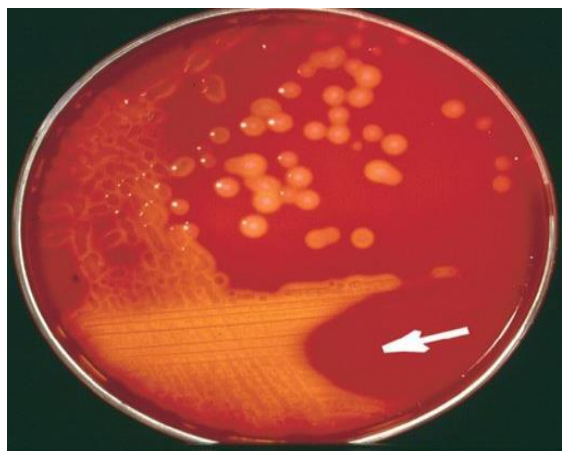

Figure 2. Streptococcus pyogenes

Streptococcus pyogenes

\section{Results and Discussion}

From the sore throat analysis conducted during 2017 in the microbiological laboratory, 1590 samples were analyzed for Group A Streptococcus $\beta$-Hemolyticus. In the total cases that are 
studied from us, $84 \%$ has been negative in there culture and $16 \%$ (299 cases) are resulted positive with presence of GAS (figure 3).

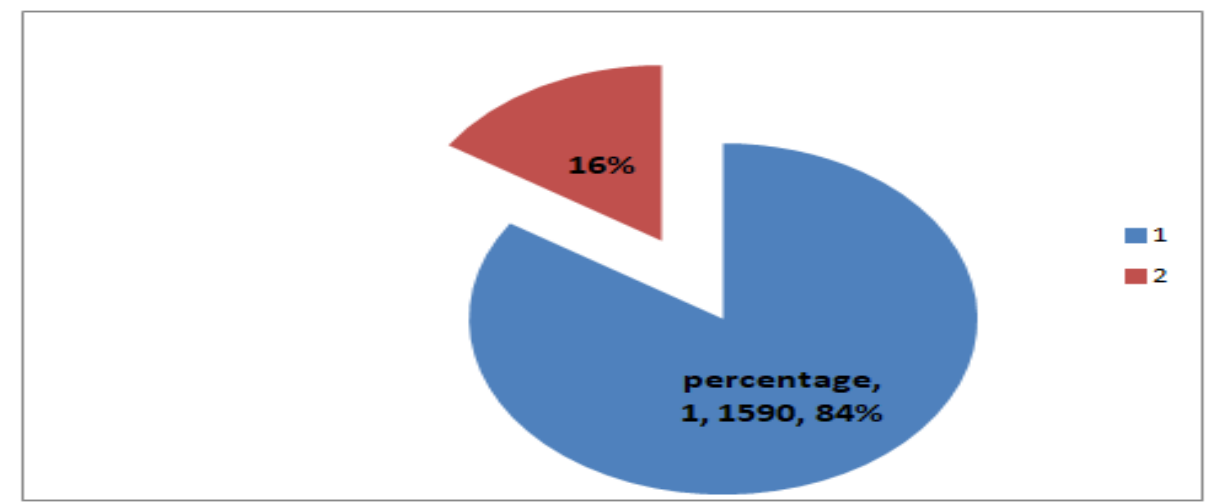

Figure 3. Percentage of cases with SBA

Analyzed age groups 0-10 years have been that which dominated the Streptococcus $\beta$ Hemolyticus of group A with 112 patients. In the 21-30 age group we had 55 patients with SBA infection, whereas in other age groups we had smaller group of infected patients with SBA infection (table 1 and figure 4).

Table 1. Frequency of SBA for each age group

\begin{tabular}{|c|c|c|c|c|c|c|c|}
\hline & $\mathbf{0 - 1 0}$ & $\mathbf{1 1 - 2 0}$ & $\mathbf{2 1 - 3 0}$ & $\mathbf{3 1 - 4 0}$ & $\mathbf{4 1 - 5 0}$ & $\mathbf{5 1 - 6 0}$ & $\mathbf{6 1 - 7 0}$ \\
\hline $\begin{array}{c}\text { Number of infected } \\
\text { patients with SBA }\end{array}$ & 112 & 42 & 55 & 43 & 27 & 14 & 6 \\
\hline
\end{tabular}

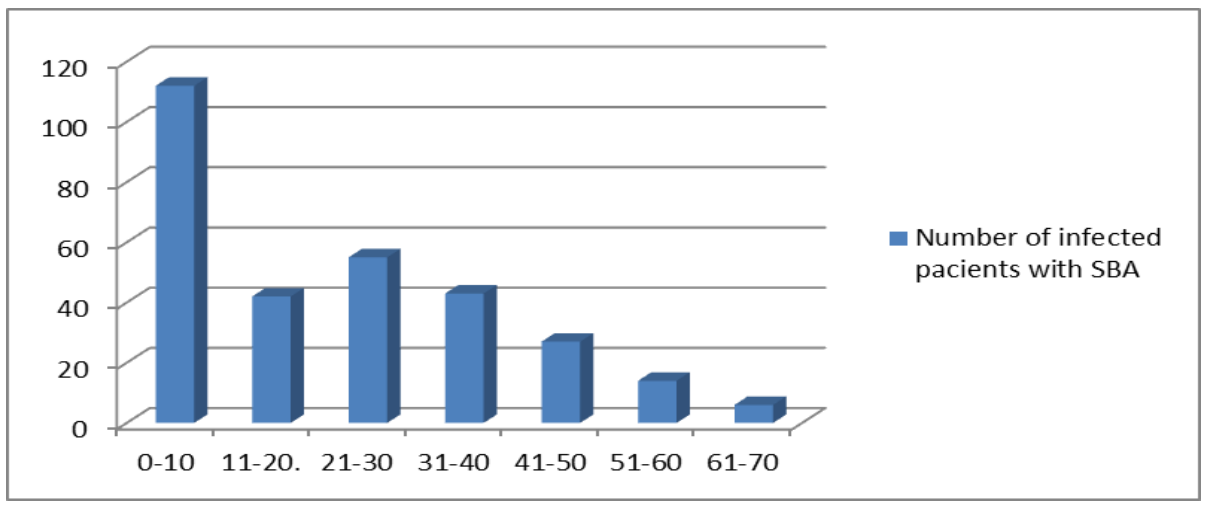

Figure 4. Number of infected patients with SBA 
In figure 5 is presented report of SBA infections by sexes which have been more present in females with 182 cases in report with males with 117 cases.

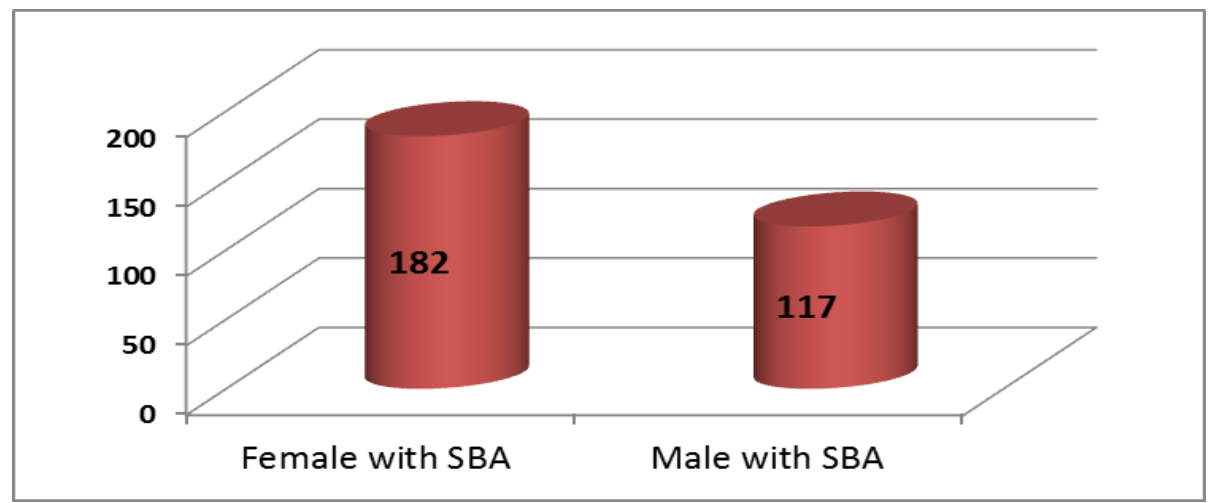

Figure 5. Report of SBA infected patients by gender during 2017

In table 3 and in figure 6 we see the frequency of analysis in different seasons of the year that indicates greater frequency of analysis during the winter with 108 cases or $36 \%$ of individuals infected with SBA and in the spring with 103 cases or $35 \%$ of individuals infected with SBA. Summer and autumn seasons have approximate value.

Table 3. Cases with SBA according to the seasons

\begin{tabular}{|l|r|}
\hline Seasons & Total \\
\hline Spring & 103 \\
\hline Summer & 42 \\
\hline Autumn & 46 \\
\hline Winter & 108 \\
\hline Total & 299 \\
\hline
\end{tabular}

\section{Cases with SBA according to the seasons}

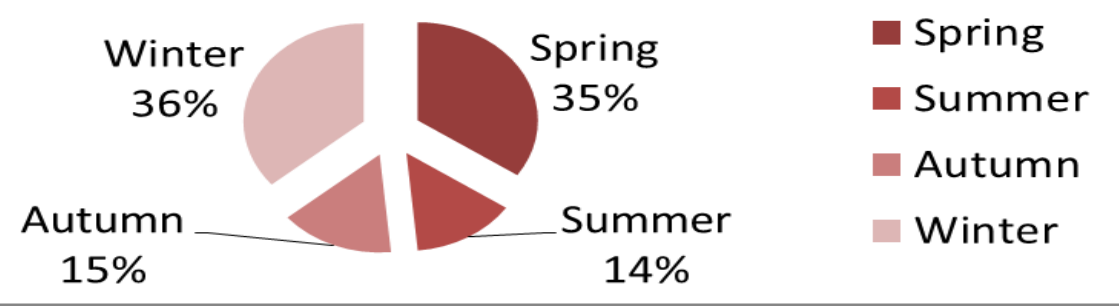


Figure 6. Cases with SBA according to the seasons

From table 4 and figure 7 it is clear that the extent of SBA infections by seasons can be seen and during the follow-up of these infections during the months of the year 2017. During the period December - February we had 108 patients infected with Streptococcus $\beta$-Hemolyticus and during the period March-May we had 103 cases infected with SBA.

Table 4. Seasonal changes of SBA infections by months

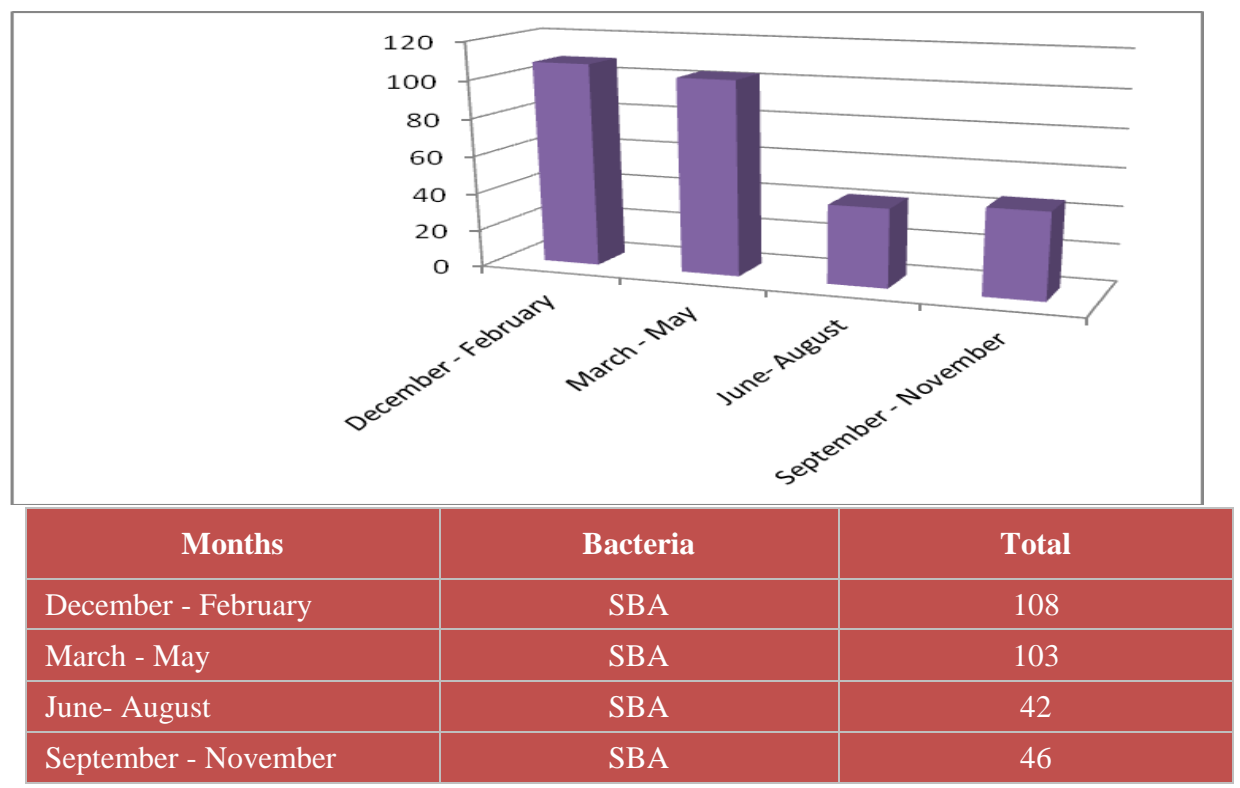

Figure 7. Seasonal changes of SBA infections by months

For all cultures isolated with SBA is made antibiogram and are used these antibiotics: penicillin, erithromycin, amoxiclav, amoxicillin, cephalexin, cefaclor, co-trimoxasole, ceftriaxone, gentamicin. The great sensitivity was in these antibiotics: penicillin, erythromycin and amoxiclav (table 5 and figure 8 ).

Table 5. Percentage of resistance of SBA in antibiotics 


\begin{tabular}{|l|r|}
\hline Erithromycin & $28 \%$ \\
\hline Amoxiclav & $21 \%$ \\
\hline Amoxicilin & $13 \%$ \\
\hline Cephalexin & $0.84 \%$ \\
\hline Cefaclor & $0.69 \%$ \\
\hline Cotrimoxazole & $0.47 \%$ \\
\hline
\end{tabular}

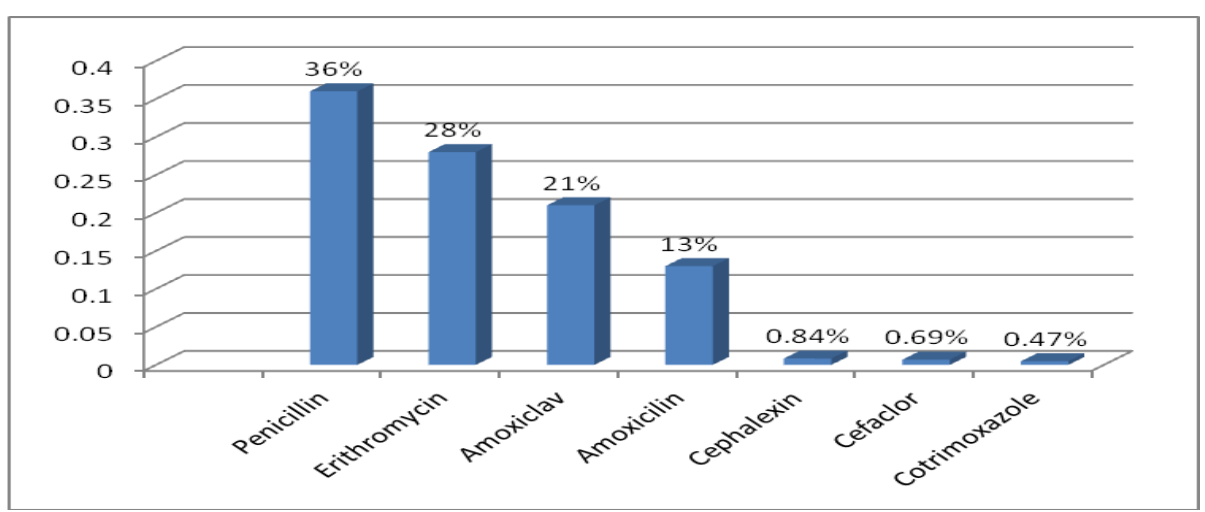

Figure 8. Percentage of resistance of SBA in antibiotics

During comparing the results of the respiratory tract infections with Streptococcus Beta Hemoliticus Group A in 2007 with those of year 2017, it was noted that in 2007 the highest number of infections was reported during the spring season and in the period autumn - winter compared to those of 2017 where the highest number was in the spring and winter (Figure 9). The number of people infected with SBA has been highest in 2007 with 315 cases (Figure 10).

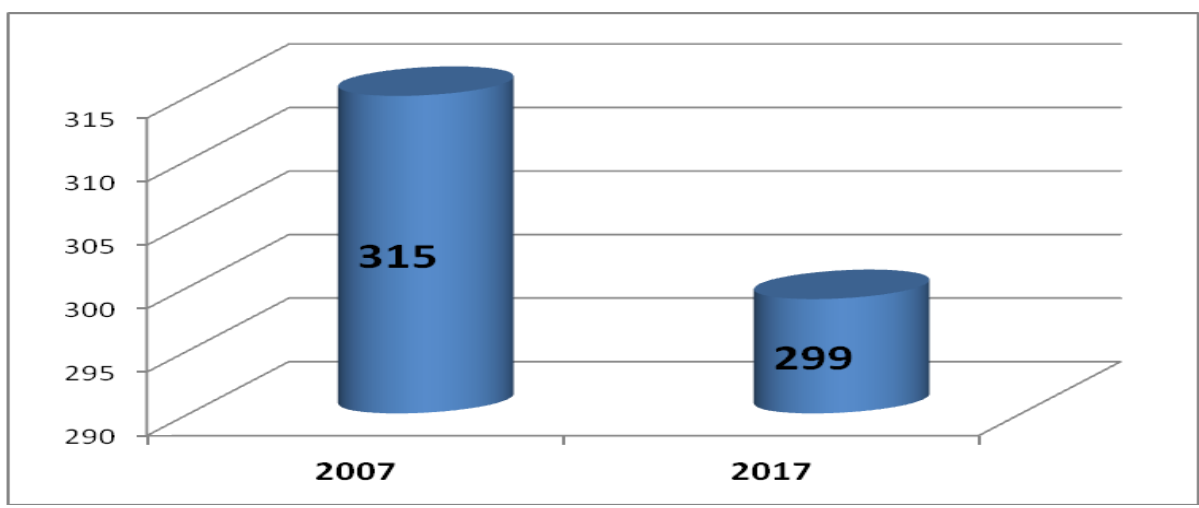

Figure 9. Cases with SBA according to the seasons during 2007 and 2017 


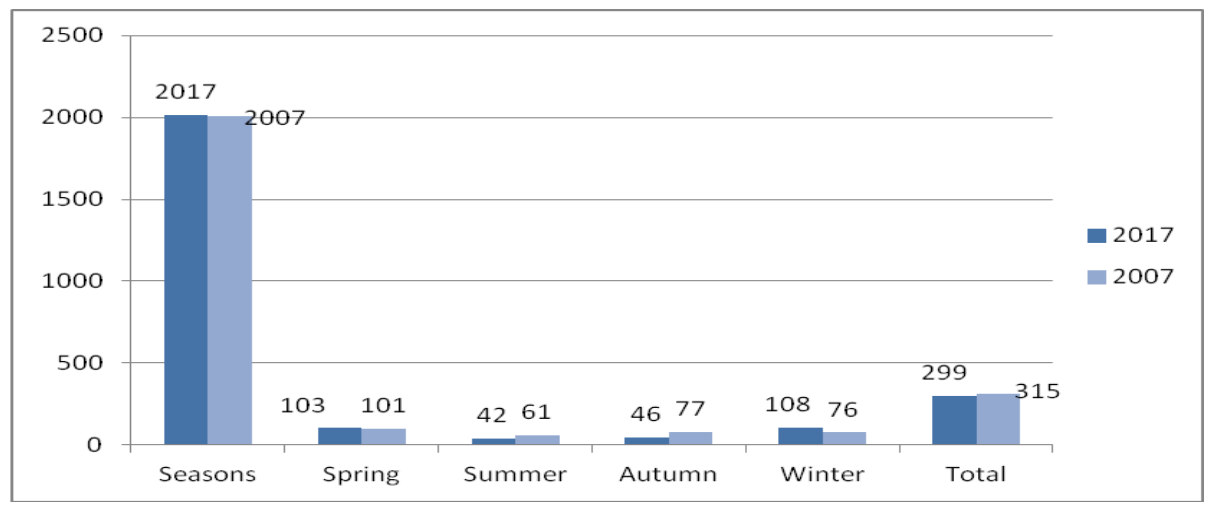

Figure 10. Number of infected patients with SBA during 2007 and 2017

\section{Conclusions}

Based on the results obtained from laboratory analysis we can conclude that Streptococcus $\beta$ Hemolyticus infections are common in upper respiratory tract infections especially at children's and adolescents.

Their isolation requires appropriate methods of collections, transportations and cultivation of specimens. This work indicated that seasonal changes directly increased the number of infected patients with Streptococcus $\beta$-Hemolyticus, especially during the winter and spring season. Individuals were analyzed by age and the $0-10$ group was more frequent with SBA infection, while in the gender classification women were more frequent with SBA.

\section{References}

1. Adam D: Group A Streptococci in 1999s, Journal of Antimicrobial Chemotherapy, 45, tropics T1, 1-2: 67-72

2. Baron S. Medical Microbiology, 4th edition. 4th ed. Baron Samuel University of Texas Medical Branch at Galveston, Galveston T, editor. Galveston; 1996.

3. Bisno AL, Stevens DL. Streptococcus pyogenes (including streptococcal toxic shock syndrome and necrotising fasciitis). In: Mandell GL, Bennet JE, Dolin R, editors. Principles and practice of infectious diseases. Philadelphia: Churchill Livingstone, 2000: 2101-2117.

4. Brien J.H,Stevens D.L., (1985). Steptococcal pharyngitis:optimal site for throat culture. J PEDIATER 109:15-22

5. Cockerill FR, III, MacDonald KL, Thompson RL, Roberson F, Kohner PC, BesserWiek J et al. An outbreak of invasive group A streptococcal disease associated with 
high carriage rates of the invasive clone among school-aged children. JAMA 1997; 277(1):38-43.

6. Chelsom J, Halstensen A, Haga T, Høiby EA. Necrotising fasciitis due to group A streptococci in western Norway: incidence and clinical features. Lancet 1994; 344(8930):1111-1115.

7. Demers B, Simor AE, Vellend H, Schlievert PM, Byrne S, Jamieson F et al. Severe invasive group A streptococcal infections in Ontario, Canada: 1987-1991. Clin Infect Dis 1993; 16(6): 792-800.

8. Lancefield RC. Current knowledge of type-specific M antigens of group A streptococci. J Immunol. 1962;89: 307-313.

9. Martin JM, Green M, Barbadora KA, Wald ER. Group A streptococci among schoolaged children: clinical characteristics and the carrier state. Pediatrics 2004; 114(5):1212-1219.

10. Outbreak of invasive group A Streptococcus associated with varicella in a childcare center -- Boston, Massachusetts, 1997. MMWR Morb Mortal Wkly Rep 1997; 46(40):944-948.

11. Papajorgji M, Kero A: Percaktimi I aerogenëve.Manual bazë mbi metodat diagnostike mikrobiologjike 2001: 22-25

12. Strömberg A, Romanus V, Burman LG. Outbreak of group A streptococcal bacteremia in Sweden: an epidemiologic and clinical study. J Infect Dis 1991; 164(3):595-598

13. Streptococcal diseases caused by group A (beta hemolytic) streptococci. In: Chin J, editor. Control of communicable diseases manual. Washington: American Public Health Association, 2000: 470-476.

14. Veasy LG, Wiedmeier SE, Orsmond GS, Ruttenberg HD, Boucek MM, Roth SJ et al. Resurgence of acute rheumatic fever in the intermountain area of the United States. N Engl J Med 1987; 316(8):421-427. 